\title{
A APRENDIZAGEM COLABORATIVA EM REDE: A CIBEREDUCAÇÃO COMO PRÁTICA ATIVISTA E TRANSFORMADORA DO APRENDIZADO NO CURSO DE ARQUITETURA
}

\author{
Alexandre Meneses Chagas \\ Murilo Santos Lacerda \\ Ronaldo Nunes Linhares ${ }^{(*)}$
}

\section{INTRODUÇÃO}

Dentre os dispositivos criados na Cibercultura, os informacionais são diferenciados dos antigos dispositivos midiáticos, uma vez que disponibilizam as informações em espaço contínuo, dependendo das estratégias de busca de cada indivíduo (LÉVY, 2010). Essas informações são constantemente modificadas pelos diversos agentes que navegam nesse mar de informação ampliado pela computação. Esses dispositivos info-comunicacionais digitais modificam as formas de relação entre os que interagem, podendo ser: “[...] um-todos, um-um e todos-todos” (LÉVY, 2010, p. 65).

Na relação "um-todos", encontramos uma semelhança ao modelo tradicional educacional, o qual Freire (2006) definiu como educação bancária. A partir da concepção dessa entende-se que o professor (um) deposita conceitos nos alunos (todos). No meio digital, a relação "um-todos" existe quando há apenas um pólo emissor da mensagem e os pólos receptores são passivos. Já no modelo "um-um", temos uma comunicação restrita, na qual apenas dois agentes interagem eliminando a possibilidade de uma colaboração na concepção da Cibercultura, a partir da qual a informação deve estar disponível para todos.

\footnotetext{
${ }^{(*)}$ Alexandre M. Chagas. Doutor em Educação (UNIT), Professor do Programa de Pós-Graduação em Educação da Universidade Tiradentes (Unit/PPED), membro do grupo de Pesquisa e Estudos em Educação, Comunicação e Sociedade (GECES). Orcid: 〈http://orcid.org/0000-0003-3459-4399>.

Murilo S. Lacerda. Mestre em Educação (UNIT), professor do curso de Arquitetura da Universidade Tiradentes, membro do grupo de Pesquisa e Estudos em Educação, Comunicação e Sociedade (GECES). Orcid: <http://orcid.org/0000-0003-3098-8366〉.

Ronaldo N. Linhares. Doutor em Ciências da Comunicação-USP, Professor do Programa de Pós-Graduação em Educação da Universidade Tiradentes (Unit/PPED), Líder do grupo de Pesquisa e Estudos em Educação, Comunicação e Sociedade (GECES). Or Cid: 〈http://orcid.org/0000-0002-3400-4910〉.
} 
O último modelo de relação entre os agentes, "todos-todos", assemelha-se aos pressupostos da Cibercultura e de uma interação colaborativa que propicia a construção coletiva do conhecimento, a qual Lévy (2011) chama de Inteligência Coletiva. Nesse espaço desenvolve-se uma “[...] prática de comunicação interativa, recíproca, comunitária e intercomunitária, o ciberespaço como horizonte de mundo virtual vivo, heterogêneo e intotalizável no qual cada ser humano pode participar e contribuir" (LÉVY, 2010, p. 128).

No ciberespaço a inteligência coletiva proposta por Lévy (2011) tem como fundamento e base social o encontro de ideias, das línguas e das tecnologias cognitivas, abstraídas de uma comunidade. Reconhece o outro como dotado de inteligência e possuidor de um saber potencializado, que se encontram como complementares, fortalecendo, portanto, a relação "todostodos".

Nessas construções coletivas, os groupwares, enquanto software ou aplicativo que apoia o trabalho em grupo e coletivamente, têm um papel muito importante. Não é mais "cada um na sua" ou "um depois do outro", agora é uma criação coletiva por meio da qual todos criam simultaneamente. Como cada palavra pode trazer diversos significados para cada usuário, para que exista uma construção colaborativa é preciso que os groupwares possam estar reunidos por redes de associações, anotações e comentários, dando o mesmo sentido a cada palavra ou texto apresentado ao grupo (LÉVY, 2011).

Diante disso, quais desafios o docente enfrenta ao construir experiências de ensino/aprendizagem colaborativas na sala de aula do ensino superior diante do contexto da sociedade em rede que caracteriza a cibercultura? Este deve ser um questionamento que já povoa há tempos o pensamento dos professores universitários, principalmente daqueles que não construíram esses saberes na formação docente inicial, nas ciências da educação e na tradição pedagógica como propõe Gauthier et al. (2006). Esses deparam-se com o desafio de ensinar tendo apenas os saberes advindos da experiência de aluno, a qual construiu ao longo da vida escolar ao participar e vivenciar ações e práticas pedagógicas de outros professores.

Pensando em contribuir com a docência no ensino superior, este artigo propõe uma reflexão sobre a prática pedagógica/docente no curso de arquitetura. Trata-se de um relato de experiência que traz em si a potência das experiências vivenciadas, construídas e reconstruídas colaborativamente com os alunos, por meio do uso da rede social digital Facebook como um dispositivo digital de construção coletiva da aprendizagem. 


\section{APRENDIZAGEM EM REDE E O PROCESSO DE COLABORAÇÃO}

Ao escolher a rede social digital Facebook e suas possibilidades de realizar um trabalho colaborativo entre os discentes de Arquitetura, imergimos no ciberespaço e na Cibercultura com o “[...] conjunto de técnicas (materiais e intelectuais), de práticas, de atitudes, de modos de pensamento e de valores que se desenvolvem juntamente com o crescimento do ciberespaço" (LÉVY, 2010, p. 17). Com o surgimento da internet e de todos os dispositivos que possibilitaram o seu desenvolvimento, a Cibercultura é responsável pela criação de novos espaços de informação e comunicação nas relações socioculturais, econômicas e políticas.

Ao pensar sobre o futuro da cibercultura e da educação no ciberespaço, Lévy (2010) coloca que um ponto importante a se observar é a velocidade do surgimento e renovação dos saberes. Eles estão modificando-se em uma velocidade tão alta que, provavelmente, o know-how adquirido no início de sua carreira profissional estará ultrapassado antes do final dela. Além de que, na relação de trabalho, a troca de conhecimento não para de crescer, sendo cada vez mais importante a produção de conhecimento e a troca dos saberes.

Outra constatação que influencia essa projeção de futuro é a possibilidade de modificação e ampliação das funções cognitivas das pessoas, uma vez que essas passam a ter memória digital. Por meio dos bancos de dados e diversos artigos digitais, a nossa imaginação perpassa por simulações de realidade, a percepção uma realidade virtual e o raciocínio sendo trocado pela inteligência artificial (LÉVY, 2010, p. 159). As mudanças nas funções cognitivas geradas pelo ciberespaço favorecem as novas competências para encontrar e utilizar a informação, e, ao mesmo tempo, transformá-la em conhecimento, seja por meio das realidades virtuais ou mesmo das simulações.

Nesse cenário, o professor pode adotar outras posturas, dentre as quais, incentivar os alunos a participarem como atores dessa inteligência coletiva e não somente como consumidores do conhecimento disciplinar. Escolas e universidades tornam-se espaços de legitimação dessas formas de reconhecer os saberes adquiridos na vida social dos alunos, já que eles aprendem também fora do ambiente acadêmico e escolar (LÉVY, 2010).

A partir das necessidades de mudanças da sociedade e dos alunos por postura de uma aprendizagem ao longo da vida, surgem novas proposições sobre a aprendizagem. O Conectivismo, por exemplo, defendido por Dowens (2007) e Siemens (2005), que coloca a aprendizagem como um processo responsável por ligar nós especializados ou fontes de informações. Informações estas que podem estar em dispositivos não humanos, tendo na manutenção de conexões um ponto fundamental para a aprendizagem contínua, em que desenvolvem uma habilidade fundamental de 
identificar conexões entre as áreas, ideias e conceitos dentro de seus interesses. A própria tomada de decisão de qual informação irá utilizar é considerada, pelo Conectivismo, um processo de aprendizagem.

As teorias de aprendizagens e as práticas docentes tradicionais existentes não conseguem atender de forma satisfatória a essa nova realidade (SIEMENS, 2003). No entanto, dentre as teorias existentes que se apresentam como solução mais adequada para uma aprendizagem efetiva, nenhuma resolve efetivamente as questões que emergiram da relação dos sujeitos com as tecnologias digitais de informação e comunicação.

Para Siemens (2003), durante a aprendizagem temos alguns processos de componentes distintos: exploração, tomada de decisão, seleção. Essas são atividades anteriores à experiência de aprendizagem, momento em que adquirimos o conhecimento que nos faltava para resolver algum tipo de problema ou resolver uma tarefa (SIEMENS, 2003). Para esse autor, mesmo durante e após esse aprendizado de experiência, as avaliações estão ocorrendo para identificar se, de fato, o aprendizado necessário para executar a tarefa aconteceu.

Para cada fase percebe-se que existem necessidades diferentes e inerentes a cada uma. Na etapa da aprendizagem preparatória, anterior à experiência de aprendizagem, o aluno precisa de bons aplicativos informacionais para facilitar a exploração, a seleção e a tomada de decisão; no processo da experiência da aprendizagem utiliza-se o conteúdo estruturado e diálogo com pessoas especializadas; e na fase de avaliação exige uma discussão informal, reflexão e autoexpressão.

O aprender não está somente no usuário, está em outros indivíduos, nas redes sociais, nas organizações. É uma forma diferente, mediada pelas tecnologias, de aprender com outros agentes. Considerando essa possibilidade de aprendizagem por meio de outros agentes nas redes, as mídias sociais digitais, entendidas aqui como interfaces disponíveis na internet para criar redes de pessoas que interagem de acordo com interesses comuns.

Na percepção de Crook (1998), entre a aprendizagem cooperativa e colaborativa existe uma tênue linha em suas diferenças, sendo muitas das vezes difícil de identificar. Se um grupo de discentes reúne-se para realizar um trabalho de determinada disciplina, temos nesse caso uma representação de aprendizagem cooperativa. Pois, existem as normas do referido trabalho que foi determinado pelo professor e, dentro do grupo, mesmo de forma inconsciente, começa a divisão de tarefas, demonstrando a existência de hierarquia nesse processo, mesmo que eles estejam utilizando a opção de grupo do Facebook.

No entanto, se um grupo de discentes resolve utilizar a internet para criar um grupo no Facebook com a intenção de trocar informações e indicações sobre determinada disciplina, percebe- 
se, mesmo de forma inicial, uma hierarquia por parte do discente que criou o grupo, sendo ele o responsável e ditando as regras. Porém, a falta de hierarquia será identificada no momento em que os discentes iniciarem a troca de informações, sem a existência de uma hierarquia para tal e cada um poderá postar à vontade e de forma independente. Perceba que os dois grupos têm objetivos comuns: a troca de informações.

Os estudos sobre a aprendizagem cooperativa contribuem para definir uma estrutura de motivação e de organização para um programa global de trabalho em grupo, enquanto que os estudos sobre a aprendizagem colaborativa incidem nas vantagens cognitivas derivadas dos intercâmbios mais íntimos que se realizam ao trabalhar juntos (CROOK, 1998, p. 168).

Na perspectiva de Panitz (1997), a colaboração é uma filosofia de interação e um estilo de vida social em que cada um é responsável pelas suas ações, inclusive pela sua aprendizagem. Sendo assim, a aprendizagem colaborativa não é apenas uma técnica utilizada dentro da sala de aula como geralmente é o caso da aprendizagem cooperativa.

Segundo Oxford (1997, p. 447) citando Dewey, "[...] os alunos não aprendem de forma isolada, o indivíduo aprende por fazer parte da envolvente comunidade e no mundo como um todo". Ainda na perspectiva do pensamento de Dewey, citamos Schön (2000), quando afirma que o discente aprende fazendo e refletindo sobre seu fazer, sobre sua ação, aperfeiçoando-a. De tal modo, os docentes devem ser mais orientadores para o conhecimento dentro da formação para um profissional reflexivo, por meio da qual o próprio discente poderá refletir acerca de suas ações, descobrindo o que contribui ou não para a sua aprendizagem. Essa aprendizagem reflexiva, defendida por Schön (2000), trabalha a perspectiva de que, ao refletir sobre as suas práticas, esses profissionais possam desenvolver seus pensamentos e ações.

Sendo assim, temos na aprendizagem colaborativa uma vantagem quando consegue incorporar a ideia da aprendizagem reflexiva de Schön (2000), quando o grupo consegue refletir sobre suas práticas. Esse aprender a prática por meio de aulas práticas tem a característica de aprender fazendo, seja virtualmente ou não.

\section{PROPOSTA METODOLÓGICA PARA UMA INTERVENÇÃO REFLEXIVA}

A metodologia definiu-se como pesquisa-ação/intervenção, por meio da qual as ações pensadas, planejadas e implantadas foram pensadas/repensadas pelo professor e desenvolvidas com a colaboração dos alunos na rede social digital Facebook. Os sujeitos envolvidos participavam fomentando as discussões ou participando delas, acompanhando, observando o processo e 
analisando seus resultados. Para Thiollent (2009), a pesquisa-ação implica numa organização que, para além da convergência de interesses, requer legitimidade dos diferentes atores, bem como sua autonomia e liberdade de expressão. Valoriza a interação e a busca de autonomia. Professor/Pesquisador e alunos membros da comunidade estudada operam em colaboração em ações que não são transformadoras, mas que abrem um leque de possibilidades para o futuro. Autores e atores da pesquisa encontram-se reciprocamente implicados.

A participação, coaprendizagem e transformação na pesquisa-ação, mesmo que não alcance a conclusão, dá início a um processo de conscientização dos atores participantes. Como maior objetivo da pesquisa-ação, Thiollent $(2009$, p. 16) identifica "produzir novas informações, estruturar conhecimentos e delinear ações", baseados em observação e questionamentos. Para ele, a pesquisaação é de orientação interrogativa-crítica. É interrogativa por dar ênfase ao questionamento acerca da situação e é crítica no sentido da não aceitação das explicações espontâneas.

A pesquisa-ação se aplica neste estudo, ainda, por ser um método adaptável, que auxilia pesquisadores e usuários a lidar com a inserção de conhecimentos na prática. Nela, o uso da linguagem assume papel importante e significativo para identificação e interpretação da mensagem (THIOLLENT, 2009).

Inseridos nesse contexto, identificamos elementos característicos da pesquisa-ação de cunho formativo para a docência, uma vez que, durante o processo, há construção de saberes docentes por meio da reflexão acerca das ações planejadas e ajustadas no decorrer de diversas experiências realizadas por nós, sendo algumas delas discutidas mais adiante e denominadas de esboços um, dois, três e quatro. Nesse viés, atentamos para a formação do professor como uma

[...] relação complexa e interativa entre as histórias de vida, formação inicial e continuada, e as aprendizagens construídas ao longo da carreira e do exercício da profissão, nas quais que o docente interage e aprende com seus estudantes, seus pares, gestores, com a comunidade escolar e com a sociedade mais ampla (SANTOS, 2014, p. 71).

A opção por uma pesquisa de intervenção dá-se porque proporciona maior familiaridade com o problema. Para essa finalidade foi desenvolvida uma pesquisa bibliográfica em referências impressas e eletrônicas, com vistas à fundamentação teórica na busca de compreender os conceitos que permeiam as relações estabelecidas no contexto da cibercultura. Com isso, objetivou-se conhecer com maior aprofundamento os aspectos da situação determinada, configurada aqui pela construção do conhecimento por meio de práticas colaborativas na rede social digital Facebook. Sua natureza aplicada por possibilitar, a partir dos dados e informações construídos, a geração de 
novos conhecimentos para aplicação prática (SILVEIRA, 2009). Para tanto, foi constituída de nove fases, entre planejamentos e ações, planos e croquis.

Na primeira delas, para identificar informações sobre o acesso dos discentes à internet e às redes sociais, foi necessário utilizarmos questionários fechados para levantando de dados quantitativos, porém, a abordagem da pesquisa é qualitativa, pois preocupamo-nos com a compreensão acerca do que pensam os alunos, como um grupo social específico.

Com base nos dados registrados a partir do primeiro questionário, a segunda fase da pesquisa contemplou os planos das ações. Reflexões acerca dos conteúdos que deveriam ser trabalhados e de que maneira poderiam ser abordados, identificando e analisando as possibilidades, culminando em croquis para a resolução do problema. Para essa fase, também foram consideradas as reflexões sobre as experiências teste, por meio das quais efetuamos as modificações necessárias de acordo com as falhas e os acertos registrados.

A terceira fase englobou o desenvolvimento de atividades no Facebook, nas quais intervimos fomentando a discussão, captando o fluxo das participações e interagindo com os alunos. Utilizamos como instrumento a observação participante, em que “[...] o observador não é apenas um espectador do fato que está sendo estudado, ele se coloca na posição e ao nível dos outros elementos humanos que compõem o fenômeno a ser estudado" (RICHARDSON et al., 2011, p. 161). Dessa maneira, foi possível obter as informações no momento em que ocorreram e, assim, foi possível efetuarmos ajustes no processo, com o intuito de mantermos crescentes as participações e estimular as interações e a colaborações.

Após o primeiro bloco de atividades, na quarta fase da pesquisa, aplicamos um segundo questionário, visando obter dos alunos uma avaliação do processo inicial e sugestões que pudessem colaborar com os croquis do segundo bloco de atividades, planejados na quinta fase do estudo.

Semelhante à terceira, a sexta fase foi caracterizada pelo segundo bloco de atividades, mas com ajustes metodológicos nos croquis baseados nas análises sobre o primeiro bloco. Na sétima fase aplicamos o último questionário, quando os alunos puderam apresentar suas críticas ao processo e propor sugestões para experiências futuras. A oitava fase contemplou a formação de um grupo focal, que se “[...] baseia em gerar e analisar a interação entre participantes” (BARBOUR, 2009, p. 20). Lançamos questões para o grupo, sem direcioná-las a indivíduos específicos, no intuito de captar percepções sobre a atividade e a aprendizagem construída coletivamente. Nos questionários não foi necessária a identificação dos respondentes, a fim de conferir privacidade, 
uma vez que, sem identificarem-se, teriam maior liberdade para expor as suas observações e avaliações do processo.

Por fim, utilizamos elementos da análise de conteúdo proposta por Bardin (2011), como as técnicas de análise categorial (desmembramento do texto e reagrupamento por temas) e análise das relações (extrair a relação entre os elementos das mensagens). Os dados foram organizados e categorizados mecanicamente (para gerar tabelas que expressam os dados quantitativos) e digitalmente, com o uso do software de análise qualitativa de conteúdo WebQDA, fornecendo subsídio para as análises qualitativas.

A experiência ocorreu no primeiro semestre letivo de 2017, com 59 alunos da disciplina Projeto de Arquitetura e Urbanismo I (PI) do curso de Arquitetura da Universidade Tiradentes. As atividades foram trabalhadas como parte constitutiva da Medida de Eficiência (ME) da primeira unidade da disciplina, com uma pontuação valendo 2,0 pontos, correspondente a $20 \%$ da nota da unidade.

Parte das informações foram obtidas por meio de um questionário aplicado ao final das atividades. Os dados serviram para identificar as impressões sobre as participações e a avaliação do processo (dados qualitativos) por parte dos alunos. A fim de proteger a privacidade dos sujeitos participantes e deixá-los à vontade para responder com suas críticas, sugestões e percepções, optamos por identificá-los como "Discente $(1,2,3, \ldots, n)$ ".

As ações começaram a ser executadas no início do período de aulas curriculares. O primeiro contato com os alunos foi para explanar sobre o objetivo da pesquisa e a importância da colaboração dos discentes daquela turma como sujeitos, destacando a importância deste estudo para a ciência e para o aperfeiçoamento da prática docente, bem como do processo de aprendizagem ligado àquela disciplina e à formação do arquiteto. Todo o planejamento e os pormenores das várias etapas foram apresentados, bem como os métodos para construção dos dados e apresentação dos resultados.

A partir de então, procedemos à criação do grupo fechado no Facebook e, por meio do Magister, portal da universidade, encaminhamos mensagem com a instrução para que cada aluno solicitasse ingresso no grupo, denominado "Projeto I_2017”. Após o ingresso, no intuito de propiciar celeridade ao processo, cada participante tinha a possibilidade de adicionar outros participantes, desde que esses estivessem matriculados na mesma turma da disciplina.

Os dados das postagens no grupo do Facebook foram categorizados e analisados com o auxílio do software de análise qualitativa de conteúdo WebQDA. As análises visaram os registros 
das participações, as colaborações e as interações sob as perspectivas preconizadas por Lévy (2010): professor-aluno; aluno-aluno; aluno-professor; professor-alunos; e alunos-alunos.

\section{ATIVIDADE DE BUSCA DE REFERENCIAL}

A atividade proposta teve por objetivo desenvolver três competências inerentes à produção arquitetural que acreditamos serem importantes para uma boa atuação profissional, a saber: busca por referencial projetual; estudos volumétricos por meio de maquetes físicas; e pensamento sobre a totalidade do edifício, envolvendo não somente aspectos funcionais como também estéticos e tecnológicos. A atividade consistiu em assistir ao filme 'Esboços de Frank Gehry' para subsidiar a discussão sobre questões propostas por nós acerca de aspectos inerentes ao filme e à atuação profissional de arquiteto.

Escolhemos esse documentário do estadunidense Sydney Pollack porque discute não somente os preceitos projetuais do arquiteto Frank Gehry, mas também a sua maneira de projetar. Após pesquisar nas mais diversas manifestações culturais, em busca de inspiração, Gehry inicia o desenvolvimento dos seus projetos com a elaboração da maquete volumétrica, cuja materialização espacial acreditamos em poder proporcionar uma melhor visualização do porvir da arquitetura, fator que pensamos ser primordial para ser aprendido nessa disciplina. Sua arquitetura apresenta tecnologia de ponta, desde o processo de criação até a execução da obra, o que torna os seus processos bastante envolventes.

Postado o link do filme (http://bit.ly/videogehry), este foi visualizado por todos e recebeu 6 curtidas. Embora não possamos afirmar que todos assistiram, registramos 39 postagens de 13 alunos, intercaladas por 26 postagens nossas, totalizando 65 postagens na atividade. Todas mostraram-se positivas e a discussão permeou as questões suscitadas no enunciado da atividade. $\mathrm{O}$ aluno mais participativos foi o [Discente 16], que contribuiu com 7 postagens, e os [Discentes 9, 10 e 12] não contribuíram com nenhuma postagem.

Grande parte dos textos das postagens recuperaram passagens do filme e descreveram as características de alguns edifícios que foram retratados, talvez como maneira de comprovar que o documentário foi assistido e demonstrar que, de alguma maneira, houve compreensão da mensagem. Identificamos que as postagens apresentaram as seguintes categorias, definidas após análise dos textos: conteudistas - quando trataram sobre aspectos tecnológicos, metodologia projetual e aspectos formais, que dizem respeito à aprendizagem de conteúdos importantes para a formação do arquiteto; colaborativas - quando ampliam o conteúdo com outras pesquisas e 
disponibilizam no grupo os resultados dessas, relacionando nomes de outros arquitetos e outras mídias para acessar informações que dizem respeito à aprendizagem de competências relacionais e atitudinais; e emocionais - quando resgatam memória afetiva e elementos da sua história cultural. A maioria das ocorrências estavam centradas nas subcategorias 'metodologia projetual' e 'aspectos formais'.

Tabela 1 Categorias das postagens dos alunos na Atividade 1.

\begin{tabular}{l|l|l|l|l}
\hline Categorias & Subcategorias & Ocorrências & $\%$ Parcial & \% Total \\
\hline \multirow{3}{*}{ Conteudistas } & Aspectos tecnológicos & 6 & 1,66 & \multirow{2}{*}{13,20} \\
\cline { 2 - 4 } & Metodologia projetual & 22 & 6,02 & \\
\cline { 2 - 5 } & Aspectos formais & 20 & 5,22 & \multirow{2}{*}{3,51} \\
\hline \multirow{2}{*}{ Colaborativas } & Relaciona arquitetos & 4 & 1,05 & \multirow{2}{*}{1,67} \\
\cline { 2 - 5 } & Relaciona mídias & 7 & 2,46 & 1,67 \\
\hline Emocionais & Aspectos afetivos & 4 & & \\
\hline
\end{tabular}

Fonte: Discussão realizada no grupo do Facebook e dados tratados no WebQDA (2018).

Ao analisarmos as postagens com mais profundidade, identificamos que, em suas postagens, o [Discente 16] registrou cinco ocorrências de categoria conteudista relacionadas com metodologia projetual e três ocorrências de categoria colaborativa, sendo duas relacionando arquitetos e uma relacionando mídia. O [Discente 6], com um número menor de participações, registrou o mesmo número de ocorrências, perfazendo $2,71 \%$ da sua construção textual. Dessas, seis foram conteudistas, sendo três relacionadas com aspectos formais e três com metodologia projetual, e duas colaborativas, uma relacionando arquiteto e outra relacionando mídia.

Ao discutirem sobre 'metodologia projetual', recortamos os seguintes trechos que comprovam a atenção que tiveram acerca dos estudos volumétricos: "expressar suas ideias em croquis, maquetes" [Discente 2]; "usa a maquete para chegar ao jeito que lhe agrada" [Discente 4]; "o uso da maquete desde o princípio" [Discente 11]; "croquis e estudo físico tridimensional" [Discente 14]; e "experimentar na maquete aquilo que planejamos" [Discente 6]. Ao reportarem-se sobre 'aspectos formais', recortamos: "passasse a "brincar" com aquelas fachadas, dando movimentos incríveis" [Discente 6]; "suas obras têm características cubistas" [Discente 14]; "procurava se distanciar das formas geométricas e angulares" [Discente 2]; “estilo desconstrutivista" [Discente 7]; e "a bagunça a desordem, o desprendimento, a proximidade íntima com a arte escultural" [Discente 5]. Essas subcategorias têm uma aproximação direta entre si, uma 
vez que a metodologia mais discutida no documentário refere-se ao desenvolvimento projetual por meio de maquetes físicas ou digitais. Elas possibilitam um maior domínio sobre as características estéticas do projeto.

Em diversos momentos, os alunos ratificaram a ideia inicial que tínhamos sobre a importância da maquete para os estudos volumétricos no desenvolvimento projetual e citam essa como suporte para a criação, tal qual indica a [Discente 13] em sua primeira postagem no grupo: "Fiquei fascinada pela forma de desenvolvimento projetual, a criação através da imediata visualização utilizando maquetes de estudo, criação, pensamento, planejamento em $3 \mathrm{~d}$, como se a planta baixa apenas uma formalização da ideia. Sua arquitetura remete a arte, escultura e ultrapassa os conceitos e padrões". Os termos 'maquete' ou 'maquetes' foram mencionados 15 vezes nas postagens dessa primeira atividade e refletiram 3,88\% do textual referente à subcategoria 'metodologia projetual'.

Por ter fomentado a curiosidade sobre a produção arquitetônica do profissional em questão, o filme despertou o interesse de dois alunos em buscar mais informações sobre o assunto, o que podemos constatar por meio das postagens do [Discente 13], ao colocar o link do filme sobre o Museu Guggenheim de Bilbao, e do [Discente 14], ao socializar um vídeo sobre as obras internacionais de Gehry. Essas duas postagens possibilitaram aos demais discentes conhecerem as obras internacionais projetadas por Gehry, inclusive o Museu Guggenheim de Bilbao, na Espanha, um dos maiores ícones da arquitetura contemporânea.

Sem fugir do contexto, a discussão não ficou centrada na produção de Gehry. Dois discentes postaram no grupo links com vídeos que tratavam sobre outros arquitetos internacionais (Zaha Hadid e Mario Botta) que se relacionavam pela maneira de pensar seus projetos. Como afirma o [Discente 6], as obras de Gehry retratadas no filme fizeram-na despertar a memória e acionar o seu repertório imagético quando destaca que a fez aprofundar na busca por conhecimento e realizar uma relação entre Gehry e Zaha Hadid.

Já o [Discente 16] destaca a maneira do arquiteto Mario Botta elaborar e apresentar seus projetos, apontando a intenção de "relacionar a forma que é representada seus projetos, em maquetes e croquis". Ao relacionar uma atividade produzida em outra disciplina, do período anterior, ressalta a importância de conhecimento prévio, dos subsunçores propostos por Ausubel (2003), necessários para o bom andamento de Projeto de Arquitetura e Urbanismo I. Outra passagem em que percebemos esse ponto é quando o [Discente 6] sinaliza que "[...] conhecemos pois já abordamos em sala de aula [...]”. Assim, ressalta a familiaridade com o conteúdo e tenta 
resgatá-lo junto com os colegas. Por se tratar de 'projeto', anteriormente a esta disciplina, conteúdos de desenho técnico, desenho livre e estudos da percepção e da forma tornam-se pré-requisitos necessários.

Dessa maneira, os [Discentes 6 e 16] problematizaram a atividade e foram além das ações propostas, participando de maneira colaborativa ao levarem para a discussão outros grandes nomes da arquitetura internacional e, ainda, mídias que convidaram os interessados a reportarem-se a outras informações. Essas ações ainda pontuam o hibridismo possibilitado pelo Facebook, facilitando o entrelaçamento de mídias digitais que, para além do acesso à informação, podem corroborar na aprendizagem de acordo com Lévy (2014, p. 154), quando nos diz que "as trocas mais construtivas consistem em mensagens curtas que apontam para uma URL contendo dados multimídia".

Observamos que, embora a maioria das postagens contivesse um grande volume textual, talvez as mensagens mais curtas, com indicações de outras fontes de pesquisa, possibilitassem a construção de um maior repertório informacional, abrangendo outras experiências profissionais e perspectivas projetuais. Também destacamos a ampliação do protagonismo discente, ao tomarem a responsabilidade de colaboração com o aprendizado dos colegas, trocando informações, disponibilizando produções, socializando informações e, por conseguinte, construindo conhecimento. Desviando o foco da figura do professor e assumindo o papel de centralidade na aprendizagem, pelo menos nesses momentos especificamente, acabam por conquistar as competências propostas pela atividade.

Ainda que houvesse a possibilidade de acesso as mesmas informações por outros meios, utilizar esta rede social digital - Facebook - possibilitou, ao grupo, o entrelaçamento de dados digitais de maneira instantânea e ubíqua, por meio dos quais lhes foi permitido checar as informações e integrá-las aos seus sistemas pessoais de conhecimento, de acordo com as suas conveniências.

A maioria das postagens dos alunos, naquele momento, estava centrada na interação 'alunoprofessor', numa reprodução viciosa da interação presencial, comum na rotina de sala de aula. Buscamos constantemente combater esse tipo de interação no decorrer das atividades, buscando uma perspectiva de aprendizagem na qual os alunos mantivessem uma postura ativa. Não excluímos, desse processo, a percepção sobre a interação 'aluno-tecnologia', visto que essa foi necessária para a realização das relações no campo virtual, por meio de smarphones, tablets e 
notebooks. Quando o [Discente 8] traçou um paralelo entre a obra de Gehry e de Oscar Niemeyer, despertou o interesse de alguns colegas em interagir no eixo 'aluno-aluno'.

Nas ponderações, eles relacionam as obras desses dois arquitetos por meio de elementos que os aproximam e citam: a ordem do desenvolvimento, percebido ao destacarem que "[...] a estrutura por fora primeiro para depois desenvolverem as plantas [...]" [Discente 8], e a monumentalidade, ao destacarem “[...] as grandes proporções, a exuberância e o movimento das formas” [Discente 6]. Brincaram também quando pontuaram que "[...] devem pensar na melhor forma possível de quebrarem a cabeça dos engenheiros [...]" [Discente 16], certamente, na tentativa de aludir à complexidade dos volumes e das técnicas construtivas adotadas para as obras de ambos arquitetos: concreto armado, estrutura metálica, painéis de aço etc.

Para finalizar, gostaríamos de resgatar quatro registros pontuados sobre 'aspectos afetivos': “[...] onde traga sensações às pessoas que passarem e olharem suas obras [...]” [Discente 2]; “[...] nos traz diversas emoções ao contemplar suas obras [...]” [Discente 5]; “[...] suas obras são consideradas esculturas, obras de arte que impressionam [...]" [Discente 11]; e "[...] transmite toda uma história, toda uma vivência em cada detalhe do edifício [...]” [Discente 15]. Embora com pouca representação textual (1,67\% do total), essa categoria é de grande significação projetual, pois está no cerne da arquitetura e foi pouco abordado pelo grupo, o qual esteve mais atento às questões tecnicistas.

\section{AVALIANDO A PRÁTICA: CONCLUSÕES INCONCLUSIVAS}

Ao final das práticas desenvolvidas no semestre, encerramos as atividades no Facebook e aplicamos um grupo focal, que foi realizado após o final das atividades curriculares e registrado por meio do software de gravação do Iphone 7. Iniciamos com questões previamente estabelecidas que, no decorrer da conversa, suscitaram outras questões. Contamos com a participação de todos os 10 discentes que estavam ativos na turma. Naquele momento, registrávamos 1 aluno que havia trocado de curso e 05 deles que, embora estivessem matriculados na disciplina, não participaram das atividades, nem das presenciais nem das virtuais.

Ao serem questionados sobre 'como usam as redes sociais para aprender', além de tratarem sobre o Facebook, trouxeram exemplos de outras redes nas quais interagiram antes ou durante o processo e que, de alguma maneira, aprenderam por meio delas, citando: Pinterest, Youtube e até mesmo o extinto Orkut. Nessas imersões nas redes, os alunos pontuam como um dos aspectos de interesse a possibilidade de compartilhamento (de arquivos, de imagens, de sites e de outras 
'comunidades'). Muitos nunca tinham utilizado o Facebook com uma perspectiva de aprendizagem ou, pelo menos, voltado para a educação. Por meio das atividades, além de conhecer esse viés possibilitado por essa rede, nas discussões, puderam ter conhecimento de outras plataformas sugeridas pelos colegas. Isso nos faz perceber a presença da colaboração.

A colaboração é percebida e indicada por eles não somente quando há sugestão direta, mas também quando há exposição de ideias ou opiniões pessoais dos colegas, pois, reconhecem que por meio dessas podem alterar seus pontos de vista e contribuir com os demais. Atestaram que por meio das redes sociais acabaram por se interessarem pela pesquisa, pela 'busca', pois a partir das postagens tiveram acesso a informações antes desinteressantes, ou mesmo desconhecidas, e que instigaram a curiosidade sobre aprender mais, a ler e a compartilhar, corroborando com a aprendizagem.

Para além de favorecer a interação e a colaboração por meio do Facebook, esta plataforma também funcionou para o grupo como uma espécie de repositório. As conversas, os links, as imagens e os vídeos postados sobre os mais variados assuntos estiveram disponíveis para acesso a qualquer momento. Principalmente quando foi necessário resgatar alguma informação que, em outro canal, talvez não fosse tão facilitado e, dessa maneira, atentam:

Ao serem interrogados sobre atividades desenvolvidas por meio de redes sociais em outras disciplinas, 90\% (9 alunos) atestaram nunca terem experimentado. Os alunos não perceberam aspectos negativos para a metodologia e o maior atrativo para eles foi, de fato, a prática da colaboração. Aprender com as ideias dos colegas, com as sugestões dos colegas, com as trocas de informação.

Constatamos a convergência para o protagonismo na aprendizagem quando o Discente 4 destaca que “[...] todo mundo tava focado numa só coisa que é aprender". Denota, ainda, que ocorreram mudanças em seu pensamento, quando afirma: “eu pude ver com outros olhos". O que nos faz acreditar que, a partir do momento em que tiveram acesso às informações, não eram mais os mesmos indivíduos, passaram a pensar sobre novas perspectivas e, consequentemente, produziram conhecimento.

As ações, por meio do Facebook, também foram eficientes em proporcionar a aproximação entre os alunos. Em diversos momentos das atividades, percebemos que alguns alunos participavam muito próximo do término do tempo estipulado. Ao discutirmos sobre os motivos, identificamos justificativas variadas, tais quais: “[...] na hora eu não podia procurar, não podia ir atrás [...]" (Discente 13) [00:15:32], quando relacionou o 'atraso' por motivos de tempo; “[...] também foi por 
falta de costume mesmo [...]" (Discente 3) [00:16:19], sinalizando a falta de hábito em utilizar as redes sociais digitais como recurso para a educação; e "[...] uma mania do aluno tipo 'não, amanhã eu respondo' [...]”, claramente uma insinuação do hábito de procrastinar a execução das atividades estudantis.

Sobre as participações 'em cima da hora', questionamos sobre a preocupação com a qualidade do conteúdo postado, para a qual o Discente 14 [00:17:22] respondeu: “[...] no meu caso na primeira unidade eu confesso que foi exatamente assim, foi para cumprir a agenda, mas na segunda unidade, não [...] fui atrás... fiz alguns slides e acabei postando para que vocês pudessem ter [...]", indicando, no início, uma preocupação individual e um engajamento na colaboração no decorrer do processo. Mas, ainda que o discente tenha indicado pouca atenção com os conteúdos das postagens, não percebemos nas ações nada que tenha sido demérito em nenhuma postagem.

Essa passagem nos faz perceber a mudança de comportamento do aluno, a qual pode ser justificada pela reflexão e alteração constante nas estratégias docentes. Essas só foram possíveis em decorrência da observância contínua e da articulação das atividades, buscando sempre tornar o processo atraente e despertar o interesse para a participação, sem nunca distanciar dos conteúdos.

Outra questão importante foi quanto à percepção que tivemos de que, durante as atividades, o número de alunos que visualizavam era maior do que o número de alunos que participavam. Então, claramente sobre uma perspectiva de aprendizagem significativa, ao selecionar os conteúdos de interesse, o Discente 8 [00:18:44] argumenta: “[...] se eu tivesse uma dúvida sobre telhado, 'Discente 16' vai e bota um exemplo de...de jardineira...eu vou... não vou abrir...eu quero ver telhado".

Na sequência, questionamos: Apenas visualizando e/ou curtindo havia algum aprendizado? Todos responderam: “sim”. Inferimos, assim, que o aprendizado por meio das redes sociais digitais, a exemplo do Facebook, dá-se não somente nos momentos em que há participação direta por meio de postagens ou curtidas. Há aprendizado mesmo que a ação seja de 'observação', como ressalta (Discente 9) [00:19:30]: “[...] A visita dos sites... que... a maioria das postagens tinham links... e a partir disso aí dá pra ler e... e aprofundar".

Outra abordagem importante foi sobre como aperfeiçoar a experiência. Em diversas respostas eles reconhecem que se houvesse participado mais ativamente, interagindo mais, a experiência teria rendido resultados ainda melhores. Então, questionamos: por que não se movimentaram? Duas falas foram registradas: “Às vezes é tempo, né, que a gente tá fazendo projeto em casa [...]” (Discente 14) [00:25:50]; e “[...] acho que os alunos ficavam esperando alguém ir lá e 
comentar primeiro [...]" (Discente 16) [00:26:09]. Inferimos que, para alguns, as dificuldades na administração do tempo podem interferir na quantidade ou na qualidade da aprendizagem. A dificuldade em organizar o tempo para o processo de aprendizagem impacta na forma dos discentes realizarem as tarefas. Essas, se planejadas e colocadas em ordem de importância, contribuem para a organização e otimização do tempo para aprender. Mas, para outros, a dependência da participação de outros pode inferir em falta de iniciativa. De modo que esses ficam aguardando algo que possa motivá-los a colaborar e a aprender.

Ao final, atentamos para questões que poderiam ter interferido na participação dos alunos. Uma relativa à 'timidez', para a qual todos responderam "não". Outra relativa à 'vergonha ou constrangimento', que, embora a 'vergonha' não tenha impedido as participações, como atesta o Discente 4 [00:28:02] ao dizer que "Não, porque eu participei bastante", percebemos a preocupação com o 'outro' como um fator de importância para o grupo. O que pode interferir na comunicação entre eles, ou favorecendo a inserção de informações mais 'corretas', que agradam ou ajudam, ou impedindo a troca dessas informações.

Notamos ainda uma estratégia expressiva da comunicação (SFEZ, 2007), na qual o contato com o outro nos faz posicionar na condição de receptores da informação, cuja avaliação repercute imediatamente na situação.

Nesse contexto, percebemos que o Facebook pode se configurar como espaço de continuidade da sala de aula e das relações de aprendizagem. Nele, as discussões podem ser ampliadas por meio do uso de imagens e outras mídias, facilitando a participação, a interação, a colaboração e tornando o processo de aprendizagem mais atraente no meio virtual. A variedade de conteúdos possíveis de serem socializados favorece a pesquisa e diversifica as discussões. 


\section{REFERÊNCIAS}

AUSUBEL, David Paul. Aquisição e Retenção de Conhecimentos: uma perspectiva cognitiva. Lisboa: Paralelo, 2003.

BARBOUR, Rosaline. Grupos Focais. Tradução: Marcelo Figueiredo Duarte. Porto Alegre: Artmed, 2009.

BARDIN, Laurence. Análise de conteúdo. Tradução: Luís Antero Reto e Augusto Pinheiro. Lisboa: Edições 70, 2011.

CROOK, Charles. Ordenadores y aprendizaje colaborativo. Traducción de Pablo Manzano. Madrid: Ediciones Morata, 1998.

DOWNES, Stephen. What Connectivism Is [online]. 2007. Disponível em: <http://www.downes.ca/post/38653>. Acesso em: 12 jun. 2018.

FREIRE, Paulo. Pedagogia do oprimido. 43. ed. São Paulo: Paz e Terra, 2006.

GAUTHIER, Clermont et al. Por uma teoria da pedagogia: pesquisas contemporâneas sobre o saber docente. 2. ed. Ijuí: Editora Unijuí, 2006.

LÉVY, Pierre. Cibercultura / Pierre Lévy; tradução de Carlos Irineu da Costa. 3. ed. São Paulo: Editora 34, 2010.

LÉVY, Pierre. A inteligência coletiva: por uma antropologia do ciberespaço. Tradução: Luiz Paulo Rouanet. São Paulo: Ed. Loyola, 2011.

LÉVY, Pierre. A esfera semântica. Tomo I: computação cognição e economia de informação. Tradução: Daniel P. P. Costa. São Paulo: Annablume, 2014.

OXFORD, Rebecca L. Cooperative Learning, Collaborative Learning, and Interaction: three communicative strands in the language classroom [online]. The Modern Language Journal, v. 81, n. 4, p. 443-456, 1997. Disponível em: <http://hasherahibrahim. wikispaces.com/file/view/Cooperative+Learning,+Collaborative+Learning+and+ Interaction_ Three+Communicative+Strands.pdf>. Acesso em: 20 ago. 2018.

PANITZ, Ted. Collaborative Versus Cooperative Learning: Comparing the Two Definitions Helps Understand the nature of Interactive learning [online]. Cooperative Learning and College Teaching, V8, n. 2, 1997. Disponível em: <http://home.capecod.net/ tpanitz/tedsarticles/ coopdefinition.htm>. Acesso em: 20 ago. 2018.

RICHARDSON, R.J.; PERES, J.A.S.; WANDERLEY, J.C.V., Correia, L.M.; PERES, M.H.M. Pesquisa social: métodos e técnicas. São Paulo: Atlas. 2011.

SANTOS, Edméa. Pesquisa-formação na cibercultura. Santo Tirso: Whitebooks, 2014.

SCHÖN, Donald A. Educando o profissional reflexivo: um novo design para o ensino e a parendizagem. Tradução Roberto Cataldo Costa - Porto Alegre : Artmed, 2000.

SFEZ, Lucien. A comunicação. Tradução: Marcos Marcionilo. São Paulo: Martins Fontes, 2007.

SIEMENS, George. Learning Ecology, Communities, and NetworksExtending the classroom [online]. 2003.

Disponível em: <http://www.elearnspace.org/Articles/ learning_communities.htm>. Acesso em: 20 ago. 2018.

SIEMENS, George. Connectivism: A Learning Theory for the Digital Age [online]. In: International Journal of Instructional Technology \& Distance Learning. Vol 2. n. 1, 2005. Disponível em: <http://www.itdl.org/Journal/Jan_05/article01.htm>. Acesso em: 20 ago. 2018.

SILVEIRA, Denise T.; CÓRDOVA, Fernanda P. A pesquisa científica. In: GERHARDT, Tatiana E.; SILVEIRA, Denise T. (org.). Métodos de Pesquisa. Porto Alegre: Editora UFRGS, 2009.

THIOLLENT, Michel. Pesquisa-ação nas organizações. 2. ed. São Paulo: Atlas, 2009. 


\section{RESUMO}

Com o advento do digital, aconteceram algumas reconfigurações na sociedade contemporânea. Entre os campos afetados por essas reconfigurações estão a colaboração, a construção do conhecimento e a educação. Sendo assim, esta pesquisa tem por objetivo investigar as possibilidades do Facebook como espaço de aprendizagem colaborativa pelos discentes do curso de Arquitetura e Urbanismo da Universidade Tiradentes. É um estudo qualitativo fruto de uma pesquisa-formação, com os seguintes instrumentos de construção de dados: atividade pedagógica e observação participante. Os resultados permitem concluir que o Facebook contribui para os processos de aprendizagem, propiciando autonomia, protagonismo, interação e colaboração. Sendo identificada a necessidade de melhoria na administração do tempo, para obtenção de melhores respostas.

Palavras-chave: Educação. Arquitetura. Redes sociais digitais.

\section{COLLABORATIVE NETWORK LEARNING: CYBER EDUCATION AS AN ACTIVIST AND TRANSFORMING PRACTICE OF ARCHITECTURE LEARNING}

\section{ABSTRACT}

With the advent of digital, there have been some reconfigurations in contemporary society, including in the field of collaboration, knowledge building and education. Thus, this research aims to investigate the possibilities of Facebook as a collaborative learning space by students of the Architecture and Urbanism course at Tiradentes University. It is a qualitative study, the result of a research-formation, with the instruments of data construction: the pedagogical activity and the participant observation. The results allow us to conclude that Facebook contributes to the learning processes, providing autonomy, protagonism, interaction and collaboration. Being identified the need for improvement in time management, to obtain better answers.

Keywords: Education. Architecture. Digital social networks

\section{APRENDIZAJE COLABORATIVO EN RED: CIBEREDUCACIÓN COMO PRÁCTICA ACTIVISTA Y TRANSFORMADORA DEL APRENDIZAJE EN EL CURSO DE ARQUITECTURA}

\section{RESUMEN}

Con el advenimiento de lo digital, ha habido algunas reconfiguraciones en la sociedad contemporánea, incluso en el campo de la: colaboración, desarrollo del conocimiento y educación. Siendo así, esta investigación tiene como objetivo investigar las posibilidades de Facebook como un espacio de aprendizaje colaborativo por parte de los estudiantes del curso de Arquitectura y Urbanismo en la Universidad de Tiradentes. Es un estudio cualitativo, resultado de una investigación-formación, con los instrumentos de construcción de datos: actividad pedagógica y observación participante. Los resultados nos permiten concluir que Facebook contribuye a los procesos de aprendizaje, proporcionando autonomía, protagonismo, interacción y colaboración. Al identificarse la necesidad de mejorar la gestión del tiempo, para obtener mejores respuestas.

Palabras-clave: Educación. Arquitectura. Redes sociales digitales 